\title{
Acute appendicitis and acute mesenteric adenitis in children: Are they clinically distinguishable?
}

\section{Pokhrel M}

Manish Pokhrel, Lecturer, Department of Surgery, Kathmandu Medical College Teaching Hospital, Kathmandu, Nepal.

\begin{abstract}
Background: Acute appendicitis and acute mesenteric adenitis have very similar clinical presentations but radically different treatment approaches in children.

Objectives: This study aims to test the possibility of clinically distinguishing between acute appendicitis and acute mesenteric adenitis.

Methodology: A cross-sectional study was designed to recruit all children ( $<16$ years) presenting to Kathmandu Medical College Teaching Hospital with acute abdominal pain between July 2019 and November 2019. An initial diagnosis was made using clinical and laboratory data. Then all patients were subjected to ultrasound evaluation. The final diagnosis was based on the radiological or histopathological examination. The Paediatric Appendicitis score was calculated retrospectively, and a logistic regression model was used to assess the diagnostic accuracy of the clinical parameters. Results: A total of 107 patients were analysed. Among them, 31(28.97\%) had acute appendicitis and 34 (31.77\%) had acute mesenteric adenitis as the final diagnosis. The positive predictive value of clinical diagnosis was 0.91 for acute appendicitis and 0.73 for acute mesenteric adenitis, for Paediatric Appendicitis Score was 0.77 and for the predictive model to diagnose acute mesenteric adenitis was 0.89 . Ultrasound had a positive predictive value of 0.97 to diagnose acute appendicitis and 0.94 to diagnose acute mesenteric adenitis.

Conclusion: Although several clinical parameters show promise in differentiating AA from AMA, relying solely on clinical differentiation is not accurate enough to prevent diagnostic errors. It is still recommended to utilise abdominal ultrasound for the assessment of abdominal pain in children.
\end{abstract}

Key words: Appendicitis; Mesenteric lymphadenitis; Paediatric appendicitis score.

DOI: https://doi.org/10.3126/jkmc.v8i4.32385

\section{INTRODUCTION}

A cute appendicitis (AA) is one of the most common causes of acute abdominal pain in children. Among the differential diagnoses of acute abdomen, AA and acute mesenteric adenitis (AMA) have similar clinical picture. In fact, mesenteric adenitis is one of the most common findings in negative appendectomies among children'. While the treatment of AA is surgical, mesenteric adenitis is treated conservatively. Since we aspire to keep negative appendectomies to a minimum, a preoperative differentiation between these two entities is desirable.

Address for correspondence

Dr. Manish Pokhrel

Lecturer, Department of Surgery,

Kathmandu Medical College Teaching Hospital,

Kathmandu, Nepal.

E-mail: guru0941@gmail.com

ORCID: https://orcid.org/0000-0001-5216-7628
Although the recent advances in imaging have made the diagnosis of AA easier and more accurate, most of the cases of AA are still diagnosed clinically. Several scoring systems have been developed and tested to diagnose AA among which Alvarado score and Samuel's paediatric appendicitis score (PAS) are two of the commonly applied clinical scores. Both have significant sensitivity and specificity to diagnose acute appendicitis ${ }^{2-4}$.

Acute mesenteric adenitis, however, shares most of its clinical features with AA. Therefore a clinical differentiation between these two entities has been elusive. One previous study had concluded that it was not possible to differentiate these two entities clinically and that imaging in the form of ultrasonography or computed tomography should be obtained 5 . Although we are already using ultrasound to evaluate patients with pain abdomen and suspected $A A$, we feel there is a need to study, whether we can have similar diagnostic 
accuracy with clinical tests alone because radiological tests add to the cost of treatment. This might not be welcome for a resource-limited nation where every penny spent on healthcare comes from the patients' own pockets.

Therefore this study was designed to include a more extensive list of clinical variables in order to improve the probability of discovering those variables that would significantly differentiate between AA and AMA.

\section{METHODOLOGY}

This cross-sectional study was conducted between July 2019 and November 2019 at a tertiary level hospital, the Kathmandu Medical College Teaching Hospital in Kathmandu, Nepal. All patients up to the age of 16 years with acute abdominal pain were included in the study (age being the cut-off to which a Paediatric surgeon attends the patients in this institute). Children whose parents did not provide an informed consent to participate in the study were excluded. Also excluded were those patients who arrived with an ultrasound report before a clinical examination could be carried out. Ethical approval for the study was taken from the Institutional Review Committee of Kathmandu Medical College.

At first encounter, a surgical resident or a consultant made a diagnosis based on the patient's history, physical examination, blood analysis, and urine analysis. All the parameters were recorded on the proforma before further radiological tests and decision to operate were taken. These parameters included those that are required for the calculation of the Paediatric Appendicitis Score (PAS) and some other clinical features commonly associated with AMA. We do not use any scoring systems in our routine clinical practice to diagnose AA.

Ultrasonography was the primary mode of imaging and all ultrasound examinations were performed by consultant radiologists. The radiological diagnostic criteria for both AA and AMA can be seen in Table 1. For patients who underwent surgery, the final diagnosis was based on the radiological, operative findings, and the histopathological examination report. For those patients who were admitted and managed conservatively, the final diagnosis was based on the radiological findings and the response to treatment. For those patients who were not admitted but managed in the outpatient department, the final diagnosis was based on the clinical picture, radiological diagnosis, and response to treatment when re-evaluated within seven days of the first encounter. Patients who did not complete this process before a final diagnosis could be reached were excluded from the study.

The data were entered and analysed in IBM Statistical Package for the Social Sciences version 21. Analysis was done in a non-intention-to-treat basis. Continuous variables were analysed by Student's t-test and categorical values were analysed by Fisher's exact test. A two-tailed $p$-value of $<0.05$ was considered significant. Sensitivity, specificity, positive predictive value and negative predictive value were calculated for the clinical diagnosis of AA and AMA as well as the Paediatric Appendicitis Score which was calculated retrospectively during analysis. The diagnostic potential of ultrasound to differentiate AA and AMA was also calculated. The binominal logistic regression model was used to assess the diagnostic potential of each of the significant clinical parameters.

\section{RESULTS}

During the duration of the study period, a total of 112 children arrived with acute abdominal pain and were eligible for inclusion. Among all, five patients were excluded from the study because they failed to follow up with radiological reports. Therefore 107 patients were ultimately eligible for analysis.

Among these children, 33 (30.8\%) were initially suspected to have AA on clinical grounds. Twenty one of these patients underwent surgery and had AA on histological examination. There were no negative appendectomies in histology. All patients had undergone ultrasound evaluation which showed that three among the initially diagnosed 33 patients had diagnoses other than acute appendicitis. Similarly, one patient suspected of AMA met the ultrasound diagnostic criteria for AA. Thus a total of $31(28.9 \%)$ patients had AA as their final diagnosis.

Initially, 37 (34.6\%) patients were suspected to have AMA clinically, among which 27 were found to have enlarged nodes on ultrasound evaluation. On ultrasound examination, one patient had AA and nine had other diagnoses. Similarly, seven patients who had other diagnoses on initial clinical examination were found to have AMA on ultrasound examination. Thus, a total of 34 (31.8\%) children had AMA as their final diagnosis.

The summary of the diagnostic variations between the initial clinical evaluation and the final diagnosis can be seen in Figure 1. 
On evaluation of the clinical parameters, there were several components which were significantly different between $A A$ and $A M A$. Patients with $A A$ were older

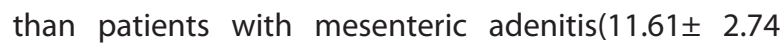
years vs $8.21 \pm 3.31$ years), and more patients reported migratory pain( $87.1 \%$ vs $2.9 \%$ ), nausea (100\% vs $82.4 \%$ ) and vomiting (87.1\% vs $32.4 \%$ ). More patients with $A A$ had rebound tenderness ( $83.9 \%$ vs $5.9 \%$ ), right lower quadrant guarding $(74.2 \%$ vs $17.6 \%)$, had cough/ hopping tenderness (74.2\% vs $0.0 \%$ ) and a significantly raised total leukocyte count(14.6 × 10\% $/ \mathrm{L} \pm 4.6 \times 10^{9} / \mathrm{L}$ vs $\left.10.6 \times 10^{9} / \mathrm{L} \pm 3.1 \times 10^{9} / \mathrm{L}\right)$ and neutrophil percentage $(81.9 \% \pm 9.4 \%$ vs $74.9 \% \pm 5.9 \%)$.

In contrast, patients with AMA had recurrent pain (41.2\% vs $0.0 \%$ ), and more of these children came with a previous history of acute mesenteric adenitis( $23.5 \%$ vs $0.0 \%)$. These patients also had a significant association with upper respiratory tract infection (URTI) within the past two weeks (58.8\% vs $9.7 \%$ ) and a history of atopy/ rashes $(32.4 \%$ vs $0.0 \%)$. The summary of the clinical parameters can be seen in Table 2.

The diagnostic value of the clinical diagnosis, the radiological diagnosis and the Paediatric Appendicitis Score (PAS) are enlisted in Table 3. Using a cut-off value of seven ${ }^{3}$ or more for the diagnosis of AA in the Paediatric Appendicitis Score the positive predictive value (PPV) for PAS was 0.77 . The positive predictive value of the model using logistic regression to diagnose acute mesenteric adenitis incorporating the significant variables was found to be 0.89 .

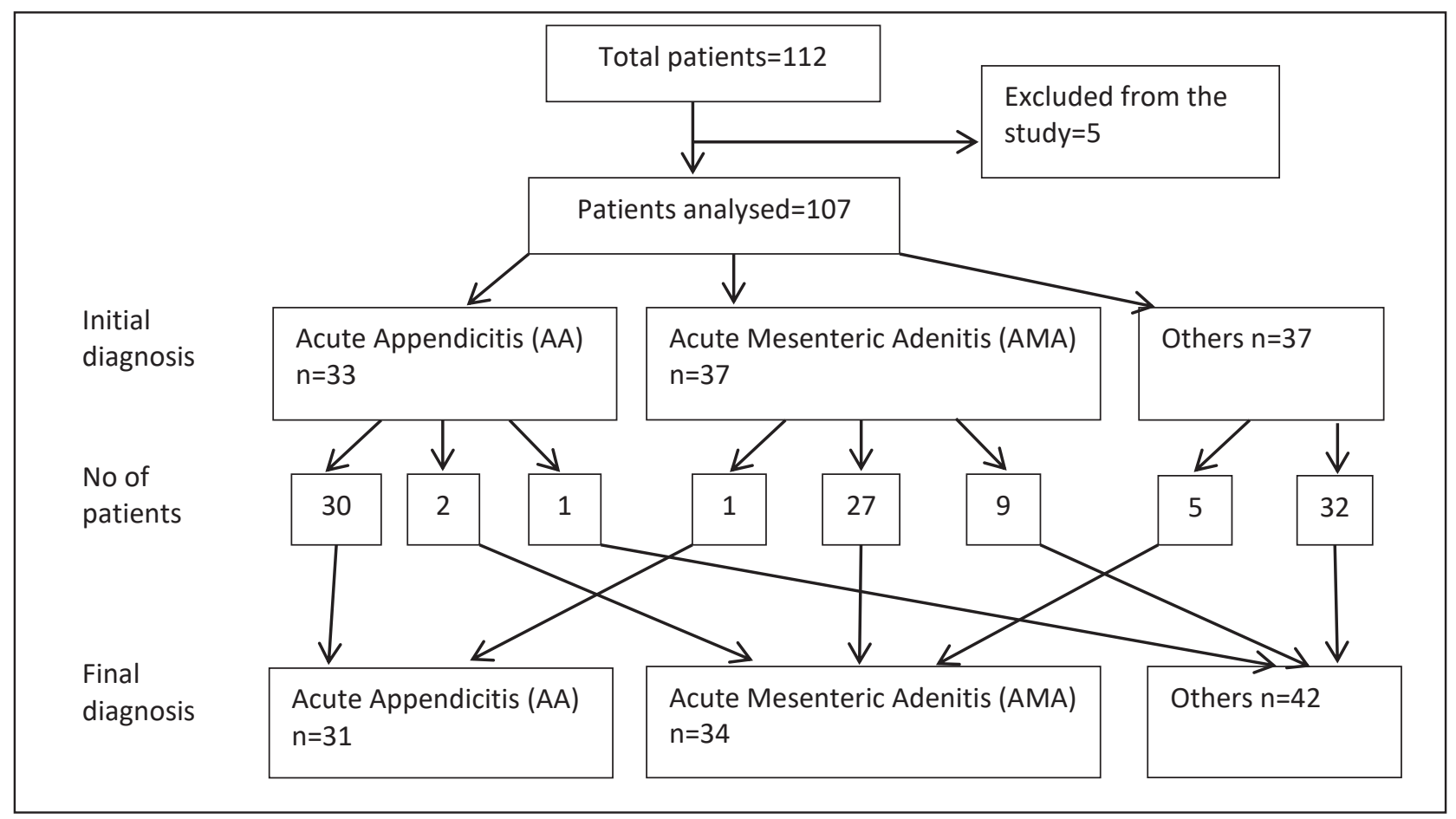

Figure 1: Diagnostic variations between the initial evaluation and final diagnosis

\section{Table 1: Radiological diagnostic criteria for AA and AMA}

\section{Acute appendicitis ${ }^{6}$}

At least one of the following:

Blind ended non-compressible tube in RLQ* (longitudinal

plane)

Diameter of appendix $>7 \mathrm{~mm}$

Presence of faecolith

Target sign in axial plane, periappendiceal collection

${ }^{*} \mathrm{RLQ}=$ Right lower quadrant of the abdomen

\section{Acute mesenteric adenitis ${ }^{7}$}

More than three lymph nodes in RLQ* with

Short axis $>5 \mathrm{~mm}$, or

Long axis $>10 \mathrm{~mm}$ 
Table 2: Differences in clinical parameters between acute appendicitis (AA) and acute mesenteric adenitis (AMA)

\begin{tabular}{|c|c|c|c|}
\hline Particulars/ Parameters & $\begin{array}{c}\text { AA N=31 } \\
\text { n (\%) }\end{array}$ & $\begin{array}{c}\text { AMA N=34 } \\
\text { n (\%) }\end{array}$ & p-value \\
\hline Age in years ( mean $\pm S D)$ & $11.61 \pm 2.74$ & $8.21 \pm 3.31$ & $0.001^{*}$ \\
\hline Male sex & $24(77.4)$ & $25(73.5)$ & 0.779 \\
\hline Duration of pain in hours(mean \pm SD) & $36.87 \pm 26.84$ & $38.24 \pm 27.32$ & 0.840 \\
\hline Migration of pain to right lower quadrant & $27(87.1)$ & $1(2.9)$ & $0.001^{*}$ \\
\hline Recurrence of pain & - & $14(41.2)$ & $0.001^{*}$ \\
\hline Nausea & $31(100)$ & $28(82.4)$ & $0.025^{*}$ \\
\hline Vomiting & $27(87.1)$ & $11(32.4)$ & $0.001^{*}$ \\
\hline Anorexia & $31(100)$ & $30(88.2)$ & 0.115 \\
\hline Previously diagnosed as AMA & 0 & $8(23.5)$ & $0.005^{*}$ \\
\hline URTI within last 2 weeks & $3(9.7)$ & $20(58.8)$ & $0.001^{*}$ \\
\hline Diarrhoeal diseases within last 2 weeks & $3(9.7)$ & $6(17.6)$ & 0.480 \\
\hline Atopy/ rashes & - & $11(32.4)$ & $0.001^{*}$ \\
\hline Maximum recorded temp in ${ }^{\circ} \mathrm{F}$ & $99.07 \pm 0.91$ & $99.22 \pm 1.47$ & 0.620 \\
\hline Right lower quadrant tenderness & $31(100)$ & $30(88.2)$ & 0.115 \\
\hline Rebound tenderness & $26(83.9)$ & $2(5.9)$ & $0.001^{*}$ \\
\hline Guarding & $23(74.2)$ & $6(17.6)$ & $0.001^{*}$ \\
\hline Rigidity & $1(3.2)$ & - & 0.477 \\
\hline Cough/hopping tenderness & $23(74.2)$ & - & $0.001^{*}$ \\
\hline Obturator/psoas sign & $3(9.7)$ & - & 0.103 \\
\hline Rovsing's sign & $14(45.2)$ & - & $0.001^{*}$ \\
\hline Total leukocytes count (x109/L) & $14.6 \pm$ SD 4.6 & $10.6 \pm$ SD 3.1 & $0.001^{*}$ \\
\hline Neutrophils percentage & $81.9 \pm$ SD 9.4 & $74.9 \pm$ SD 5.9 & $0.001^{*}$ \\
\hline
\end{tabular}

[Categorical variables are analysed by Fisher's exact test, continuous variables by Student's t-test. SD $=$ Standard Deviation, ${ }^{*}=$ $\mathrm{p}$-value<0.05]

Table 3: Accuracy of the various methods of diagnoses $(n=107)$

\begin{tabular}{lccccccccc}
\hline Diagnosis & TP & FP & TN & FN & Sensitivity & Specificity & PPV & NPV \\
\hline AA (Clinical diagnosis) & 30 & 3 & 73 & 1 & 0.97 & 0.96 & 0.91 & 0.98 \\
\hline AMA(Clinical diagnosis) & 27 & 10 & 63 & 7 & 0.79 & 0.86 & 0.73 & 0.90 \\
\hline Radiology for AA & 28 & 1 & 75 & 3 & 0.90 & 0.99 & 0.97 & 0.96 \\
\hline Radiology for AMA & 34 & 2 & 71 & 0 & 1.00 & 0.97 & 0.94 & 1.00 \\
\hline PAS $\geq 7 / 10$ for AA & 28 & 8 & 68 & 3 & 0.90 & 0.89 & 0.77 & 0.94 \\
\hline Predictive model for AMA (n=65) & 33 & 4 & 27 & 1 & 0.97 & 0.87 & 0.89 & 0.96 \\
\hline
\end{tabular}

$[T P=$ True Positive, FP= False Positive, $T N=$ True Negative, FN= False Negative, PPV= Positive Predictive Value, NPV= Negative Predictive Value]

\section{DISCUSSION}

Acute mesenteric adenitis is a disease entity that has been recognised for a long time now and the clinical features are well described in scientific literature ${ }^{8-10}$. It is a clinical condition that has a diverse group of probable aetiologies. Several viruses ${ }^{11}$ and bacteria ${ }^{12,13}$ are implicated in the causation of AMA.

Although AMA mimics AA clinically and frequently causes diagnostic errors ${ }^{1}$, there has been a paucity of research attempting to differentiate these two entities.
There have been publications describing the clinical features of these two entities separately but only a few papers dealing with the clinical differentiation between these two entities ${ }^{5,14}$.

The current study shows that there are several clinical parameters that are significantly different between these two entities. Toorenvliet et $\mathrm{al}^{5}$ had identified in their limitations that they had not included URTI while the study of Gross et $\mathrm{al}^{14}$ being retrospective in nature had failed to show an association between AMA and 
upper respiratory illness, which they have suspected to be an anamnestic detail. However, this study has shown a significant association of recent URTI with AMA.

A significant number of patients with mesenteric adenitis had recurrent attacks of pain abdomen. This was similar to the findings of Gross et $\mathrm{al}^{14}$. Vayner et al had also concluded that mesenteric lymphadenopathy was a common and often the only abnormal finding in children with recurrent abdominal pain ${ }^{15}$. Similarly, a previous diagnosis of AMA favoured more towards a current diagnosis of AMA in the current study. This feature has not been studied by both Toorenvliet ${ }^{5}$ and Gross et $\mathrm{al}^{14}$.

In this study more patients with $A A$ had rebound tenderness, guarding of the right lower quadrant and cough/hopping tenderness. These findings were similar to several other studies ${ }^{5,14,16}$. Clinical signs that are known to be associated with AA like obturator sign/psoas sign and Rovsing's sign were also positively associated with AA in this study. Total leukocyte count and the neutrophil percentage were significantly higher in the AA group as compared to children with AMA. These findings are consistent with those in other studies ${ }^{5,14}$.

One curious finding that our study identified is an association of atopy/rashes with acute mesenteric adenitis. Although speculated by some authors ${ }^{17}$, the cause-effect relation between allergy and mesenteric adenitis has not been scientifically substantiated. The author of this study had decided to include atopy as a clinical variable on the basis of personal experience of seeing several patients in the outpatient clinics with rashes who were ultimately diagnosed with AMA on ultrasound evaluation, and moreover, these were the patients who had more recurrence. This finding may warrant further study on its own.

The clinical diagnosis of AA appears very accurate in this study compared to that of the PAS. This might be attributed to the fact that PAS is limited by its components, while a clinical diagnosis incorporates several other components of the history, clinical examinations and some routine tests like the urine examination. The very low performance of PA Scan be explained by the study population of this research which incorporates all patients presenting with pain abdomen, instead of recruiting only those who are suspected of acute appendicitis. This picked up several false-positive cases. In fact, several prospective validations have failed to demonstrate the high accuracy that the original author of PAS had claimed $3,4,18-20$.
In this study, ultrasound evaluation of the abdomen demonstrably improved the accuracy of diagnosis for both acute appendicitis and acute mesenteric adenitis. This finding is consistent with several other authors $\mathrm{s}^{6,7,15,21,22}$. However, one study demonstrated that the rate of false-negative ultrasound increased with increasing PAS, and false-positive ultrasound occurred more with lower PAS, and that ultrasound findings should be integrated with clinical assessment ${ }^{23}$. As is already discussed this could have been a result of the low diagnostic accuracy of PAS as a stand-alone diagnostic test.

The logistic regression model for the prediction of AMA in this study had a positive predictive value of 0.89 . Although fairly high, this would not be considered accurate enough to guide clinical judgments. Toorenvliet et al in their study had generated a logistic regression prediction model that had a positive predictive value of $0.79^{5}$. The better value in this study might be attributed to the fact that more variables have been identified and incorporated that are significantly different between patients with $A A$ and $A M A$.

Several limitations can be identified for this study. One of the limitations is that the final diagnosis includes not only histopathological studies but also radiological diagnoses. While the histopathological test is considered the goldstandard for the diagnosis of acute appendicitis, it would not be a practical test for the diagnosis of mesenteric adenitis. Since only those patients who had a conclusive radiological or histological diagnosis were analysed, it can be concluded that the final diagnosis must have been fairly accurate. The fact that this is a single centre study and that there are relatively fewer number of patients in each arm might be the other limitations of this study.

\section{CONCLUSION}

This study has concluded that there are several clinical parameters that show promise in differentiating $A A$ from AMA. However, the clinical diagnosis of AMA is still not as reliable as that of AA. Adding an ultrasound examination as an adjunct to clinical diagnosis definitely improves the diagnostic accuracy in AMA. Therefore, until a comprehensive clinical score is available that can effectively differentiate these two entities, it is still recommended to utilise abdominal ultrasound for the assessment of abdominal pain in children.

\section{ACKNOWLEDGEMENTS}

I am grateful to all the MS residents in the Department of Surgery, Kathmandu Medical College and Teaching Hospital for their invaluable help in conducting this study. 


\section{REFERENCES}

1. Gilmore OJ, Browett JP, Griffin PH, Ross IK, Brodribb AJ, Cooke TJ, et al. Appendicitis and mimicking conditions. A prospective study. Lancet.1975 Sep 6;2(7932):421-4.[PubMed | FullText | DOI]

2. Alvarado A. A practical score for the early diagnosis of acute appendicitis. Ann Emerg Med. 1986 May;15(5):557-64.[PubMed | FullText | DOI]

3. Samuel M. Pediatric appendicitis score. J Pediatr Surg. 2002 Jun;37(6):877-81.[PubMed | FullText | DOI]

4. Goldman RD, Carter S, Stephens D, Antoon R, Mounstephen W, Langer JC. Prospective validation of the pediatric appendicitis score. J Pediatr. 2008 Aug;153:278-82.[PubMed | FullText | DOI]

5. Toorenvliet B, Vellekoop A, Bakker R, Wiersma F, Mertens B, Merkus J, et al. Clinical differentiation between acute appendicitis and acute mesenteric lymphadenitis in children. Eur J Pediatr Surg. 2011 Mar;21(2):120-3.[PubMed | FullText | DOI]

6. Schulte B, Beyer D, Kaiser C, Horsch S, Wiater A. Ultrasonography in suspected acute appendicitis in childhood-report of 1285 cases. Eur J Ultrasound. 1998 Dec;8(3):177-82.[PubMed | FullText | DOI]

7. Swischuk LE, John SD. Mesenteric adenitis-acute ileitis: A constellation of findings definable with ultrasound. EmergRadiol. 1998 Jul;5(4):210-8.[DOI| FullText]

8. Wilensky AO, Hahn LJ. Mesenteric lymphadenitis. Ann Surg. 1926 Jun;83(6):812-26.[PubMed | FullText | DOI]

9. Adams WE, Olney MB. Mesenteric lymphadenitis and the acute abdomen: report of thirteen cases. Ann Surg. 1938 Mar;107(3):359-70.[PubMed | FullText | DOI]

10. Foster AK, Jr. Disease of the mesenteric lymph nodes: its relation to appendicitis, gastro-intestinal infections and generalized diseases; report of one hundred and twenty-three cases; possible etiology and treatment. Arch Surg. 1938 Jan;36(1):28-52. [FullText | DOI]

11. Bell TM, Steyn JH. Viruses in Lymph Nodes of Children with Mesenteric Adenitis and Intussusception. $\mathrm{Br}$ Med J. 1962 Sep 15;2(5306):700-2.[PubMed | FullText | DOI]

12. Likitnukul S, Wongsawat J, Nunthapisud P. Appendicitis-like syndrome owing to mesenteric adenitis caused by Salmonella typhi. Ann Trop Paediatr. 2002 Mar;22(1):97-9.[PubMed | FullText|DOI]
13. Mair NS, Mair HJ, Stirk EM, Corson JG. Three cases of acute mesenteric lymphadenitis due to pasteurella pseudotuberculosis. J Clin Pathol. 1960 Sep;13(5):432-9.[PubMed | FullText | DOI]

14. Gross I, Siedner-Weintraub $Y$, Stibbe $S$, Rekhtman D, Weiss D, Simanovsky N, et al. Characteristics of mesenteric lymphadenitis in comparison with acute appendicitis in children. Eur J Pediatr. 2017 Feb;176(2):199-205.[PubMed | FullText | DOI]

15. Vayner N, Coret A, Polliack G, Weiss B, Hertz M. Mesenteric lymphadenopathy in children examined by US for chronic and/or recurrent abdominal pain. PediatrRadiol. 2003 Dec;33(12):864-7.[PubMed | FullText | DOI]

16. Chanchlani R. Clinical profile and management of mesenteric lymphadenitis in children-our experience. Int J Orthop Traumatol Surg Sci. 2015 Dec-May;1(1):1-4.[FullText]

17. Donhauser JL. Primary acute mesenteric lymphadenitis: a review of one hundred ninetyeight cases. AMA Arch Surg. 1957 Apr;74(4):528-35. [PubMed | FullText | DOI]

18. Bhatt $M$, Joseph $L$, Ducharme FM, Dougherty G, McGillivray D. Prospective validation of the pediatric appendicitis score in a Canadian pediatric emergency department. AcadEmerg Med. 2009 Jul;16(7):591-6.[PubMed | FullText | DOI]

19. Pogorelic Z, Rak S, Mrklic I, Juric I. Prospective validation of Alvarado score and pediatric appendicitis score for the diagnosis of acute appendicitis in children. PediatrEmerg Care. 2015 Mar;31(3):164-8.[PubMed | FullText | DOI]

20. Mandeville K, Pottker T, Bulloch B, Liu J. Using appendicitis score in the pediatric ED. Am J Emerg Med.2011 Nov;29(9):972-7.[PubMed | FullText | DOI]

21. Kaneko K, Tsuda M. Ultrasound-based decision making in the treatment of acute appendicitis in children. J Pediatr Surg. 2004 Sep;39(9):1316-20. [PubMed | FullText | DOI]

22. Pacharn $P$, Ying J, Linam LE, Brody AS, Babcock DS. Sonography in the evaluation of acute appendicitis: are negative sonographic findings good enough? J Ultrasound Med. 2010 Dec;29(12):1749-55.[PubMed | FullText | DOI]

23. Bachur RG, Callahan MJ, Monuteaux MC, Rangel SJ. Integration of ultrasound findings and a clinical score in the diagnostic evaluation of pediatric appendicitis. J Pediatr. 2015 May;166(5):1134-9. [PubMed | FullText | DOI] 